\title{
Preparation and Optimization of Esomeprazole Nanosuspension using Evaporative Precipitation- Ultrasonication
}

\author{
Vijay Agarwal ${ }^{1,2^{*}}$ and Meenakshi Bajpai ${ }^{3}$ \\ ${ }^{1}$ Department of Pharmacy, NIMS University, Shobha Nagar, Delhi highway, Jaipur, Rajasthan, ${ }^{2}$ College of Pharmaceutical \\ Sciences, Rajkumar Goel Instutute of Technology, Delhi Meerut Road, Ghaziabad (U.P.), ${ }^{3}$ Department of Pharmacy, \\ Uttarakhand Technical University, Dehradun, Uttarakhand, India
}

*For correspondence: Email: vagarwal5@rediffmail.com; Tel.: +919891383464

\begin{abstract}
Purpose: To prepare and optimize esomeprazole nanosuspension to enhance drug dissolution rate. Methods: Esomeprazole nanosuspensions were prepared by evaporative precipitation-ultrasonication method using F68 (Poloxamer 188) and F127 (Poloxamer 407) as stabilizers. Formulation and process variables (concentration of stabilizers and drug, power input and duration of ultrasonication) affecting the characteristics of nanosuspensions were optimized. The nanosuspensions were characterized for particle size, shape, zeta potential, stability and in vitro drug release study.

Results: For optimization of esomeprazole nanosuspension, the effect of some important parameters, including concentration of $\mathrm{F68}$, concentration of esomeprazole, precipitation temperature, duration of ultrasonication and power input, on particle size were investigated, and the optimal values were $0.4 \%$ $\mathrm{W} / \mathrm{v}, 3.5 \mathrm{mg} / \mathrm{ml}, 4^{\circ} \mathrm{C}, 20 \mathrm{~min}$ and $60 \% \mathrm{~W}$, respectively. Particle size was in the range of $125-184 \mathrm{~nm}$ with good zeta potential (15.9 - 25.5 mV). In vitro dissolution rate of esomeprazole was enhanced 4-fold (100\% in $60 \mathrm{~min}$ ) compared with crude esomeprazole (24\% in $60 \mathrm{~min})$, and this was due to decrease in particle size. The stability results indicate that nanoformulations stored at $4^{\circ} \mathrm{C}$ for two months showed maximum stability.

Conclusion: The results indicate the suitability of evaporative-precipitation-ultrasonication method for preparation of nanosuspensions of poorly soluble drugs with improved in vitro dissolution rate, thus potentially capable of enhancing fast onset of therapeutic activity, and bioavailability.
\end{abstract}

Keywords: Agglomeration, Esomeprazole, Ultrasonification, Nanosuspension, Drug release, Solubility, Stability

Tropical Journal of Pharmaceutical Research is indexed by Science Citation Index (SciSearch), Scopus, International Pharmaceutical Abstract, Chemical Abstracts, Embase, Index Copernicus, EBSCO, African Index Medicus, JournalSeek, Journal Citation Reports/Science Edition, Directory of Open Access Journals (DOAJ), African Journal Online, Bioline International, Open-J-Gate and Pharmacy Abstracts

\section{INTRODUCTION}

Nanosuspension is the colloidal dispersion of solid drug particles in a liquid phase having particle size below $1 \mu \mathrm{m}[1,2]$. At present time about $40 \%$ of the drugs in the development pipelines and $60 \%$ of the drugs coming directly from synthesis are poorly soluble [3]. These poorly soluble drugs require some innovative formulation approaches by which they can reach up to a sufficiently high bioavailability. There are many formulation approaches used for poorly soluble drugs, nanosuspension is also one of them. Preparation of drug in the form of nanosuspension was shown a technically simpler alternative, particularly for poorly soluble drugs [4-6]. With the help of this technique, the drugs are dispersed in water and the fineness of 
dispersed particles force them to dissolve more quickly owing to their higher dissolution pressure and leads to an increased saturation solubility [7]. In nanoformulation it is not only necessary that the drug particles be rendered into nanosize domains, but they must also be stabilized and formulated rigorously to retain the nature and properties of the nanoparticles [8].

There are mainly two approaches uses to prepare the nanosuspension: 'top down' and 'bottom up' technologies. The top down technology basically depends on mechanically attrition to render large crystalline particles into nanoparticles by various means such as wet milling and bottom up technology start from molecules, which are dissolved and precipitate them by adding the solvent to a non-solvent [9, 3]. In this research work bottom up technology is used to prepare the nanosuspension due to several advantages. These include high drug entrapment efficiency for poorly soluble drugs, narrow particle size distribution, high batch to batch reproducibility, no homogenization required, simplicity, ease of scale up and low cost equipment required [10].

The main focus of this research work is on the dissolution enhancement of poorly soluble drugs using suitable nanosuspension technology with a view to surmounting the problems associated with drug release, manufacture and stability of the drug product.

\section{EXPERIMENTAL}

\section{Materials}

Esomeprazole magnesium was obtained as a gift from Unichem laboratories, Ghaziabad, India. Pluronic F-68 and Pluronic F-127 were purchased from Sigma Aldrich Company, St. Louis, USA. PVA, PVP ${ }_{\mathrm{K}-30}$ and HPLC grade mehanol were obtained from Rankem, New Delhi, India. HPLC grade water was used throughout the study.

\section{Selection of stabilizer}

$0.1 \%(\mathrm{w} / \mathrm{v})$ solution of PVA, PVP ${ }_{\mathrm{K}-30}, \mathrm{HPC}, \mathrm{F}-$ $68, \mathrm{~F}-127$ were used as candidate to select the appropriate stabilizers for preparing esomeprazole nanosuspension. The results show that F68 and F127 allowed the production of submicronsized particles with the small diameter of 380 and $385 \mathrm{~nm}$ respectively. These two stabilizers also showed the narrow particle size distribution, in comparison of other stabilizers. So in this current study, F68 and F127 were employed as stabilizers.

\section{Preparation of nanosuspension}

Nanosuspensions were prepared by Evaporative precipitation ultrasonication method. Esomeprazole was dissolved in methanol at room temperature to form a series of organic solutions having $2,2.5,3,3.5,4,4.5,5,5.5,6,7,8,9,10$ $\mathrm{mg} / \mathrm{ml}$ of drug. Pluronic F-68 or Pluronic F-127 was dissolved in water to form a series of antisolvents ranging in concentration from $0.1-1.5$ $\% \mathrm{w} / \mathrm{v}$. Both solutions were filtered through a $0.22 \mu \mathrm{m}$ syringe filter (RanDisc nylon syringe filter). $10 \mathrm{ml}$ of organic solution was injected slowly and drop wise with a syringe into the 20 $\mathrm{ml}$ of Pluronic F-68/Pluronic F-127 solution and kept at a low temperature $\left(4^{\circ} \mathrm{C}\right)$ in an iced water bath. During injection, the mixture was stirred continuously by the mechanical stirrer at 1000 rpm for $2.5 \mathrm{hr}$. After the antisolvent precipitation, the volatile solvent was evaporated by subsequently stirred the mixture at $300 \mathrm{rpm}$ for next $3 \mathrm{hrs}$ then sample was transferred to a test tube having the capacity of $30 \mathrm{ml}$. Each of samples was treated with an ultrasonic probe (Bandelin Sonoplus, Berlin, Dermany) at various cycles ranging from $2 \times 10-7 \times 10 \%$, and power input ranging from $30-80 \% \mathrm{~W}$ ) and for various duration (5 - $40 \mathrm{~min}$ ). The probe (tip diameter, $8 \mathrm{~mm}$ ) was immersed about 10-12 mm in the liquid by which waves was travelled downwards and reflected upwards. During ultrasonication the temperature was also controlled by using ice water bath.

\section{Determination of particle size analysis and polydispersity nanosuspension}

Particle size and polydispersity index (PDI) were determined by dynamic light scattering (DLS) using a Malvern Zetasizer instrument (Malvern, UK), which allows the sample measurement in the range of 0.1 to $10000 \mathrm{~nm}$. Each measurement was performed on the diluted suspension in low volume disposable sizing cuvette at $25^{\circ} \mathrm{C}$ in triplicate. Instrument gave the size distribution on the basis of intensity and volume. The dispersant was water, and the complex refractive index used for particles was 1.33 .

\section{Evaluation of zeta potential of nanosus- pension}

The zeta potential of the nanosuspensions was measured by using an additional electrode in the same instrument used for particle size analysis (Malvern Zetasizer). For Zeta Potential determination samples of formulations were diluted with water and placed in the electrophoretic cell. Each sample was measured 
three times at $25{ }^{\circ} \mathrm{C}$ and average values were employed for measuring the response. In this study, dispersant was water. Refractive index and dielectric constant of dispersant were 1.33 and 78.5 respectively.

\section{Morphological characterization}

Nanosuspensions shown are yellowish transparent relative to the HPLC grade water, which shows the transparency but without color. The nanosuspension particles were subjected to morphological examination using scanning electron microscopy (SEM, FEI Quanta 200F with oxford-EDS system IE $250 \times$ Max 80, Netherlands). For this purpose, samples were prepared by transferring one drop of nanosuspension on a metal grid and dried under vacuum pressure, coated with gold palladium and the morphological characteristics of the particles were observed at suitable magnification $(10,000$ to $100,000 \mathrm{x})$.

\section{.In vitro drug release studies}

In vitro release of ESP from different nanosuspension formulations were studied by dialysis method using a dialysis membrane of molecular weight cutoff of $12 \mathrm{KDa}$. The Freshly prepared phosphate buffer solution $(\mathrm{pH} \mathrm{7.4)}$ and Franz diffusion cells were used in this study. Before using the dialysis membrane it was presoaked in the dissolution medium overnight and then adapted to the terminal portion of the cylindrical donor compartment. The nanosuspension $(5 \mathrm{~mL})$ containing drug, sufficient for establishing sink conditions for the assay, was placed into the donor compartment. The receptor compartment contained $15 \mathrm{~mL}$ of phosphate buffer solution of $\mathrm{pH} 7.4$ maintained at $37 \pm$ $0.5^{\circ} \mathrm{C}$ under mild agitation using a magnetic stirrer. Samples were withdrawn from the receptor compartment at predetermined time intervals and replaced by an equal volume of the medium. The amount of dissolved drug was determined using HPLC (Cecil, UK) at $\lambda_{\max }$ of $302 \mathrm{~nm}$. The mobile phase was a mixture of phosphate buffer of $\mathrm{pH} 7.6$ and acetonitrile (44: 55), pumped from the solvent reservoir to the column (Spher ODS $5 \mu \mathrm{m}$ ) at a flow rate of 1 $\mathrm{ml} / \mathrm{min}$. $R_{t}$ for esomeprazole was $3.42 \mathrm{~min}$. To examine the limiting effect of the dialysis membrane on drug dissolution and for comparison, the release profile of pure drug was also determined. For this purpose, the equivalent amount of ESP was dispersed in $5 \mathrm{ml}$ of phosphate buffer solution. Each release experiment was performed in triplicate.

\section{Stability studies}

Esomeprazole nanosuspensions were stored at $4,25{ }^{\circ} \mathrm{C}$ and room temperature (approximately $35{ }^{0} \mathrm{C}$ ) for two months, and average particle size determined using the zetasizer.

\section{Statistical analysis}

Statistical analysis of the data was carried out using Systat ${ }^{\circledR} 12$ software (Systat Software, Inc, San Jose, CA, USA). All the tests were run in triplicate and the results given as mean \pm standard deviation (SD). Mean values were compared using Student's t-test. Differences were considered statistically significant at a level of $p<0.05$.

\section{RESULTS}

\section{Effect of drug and stabilizer concentration on particle size}

The effect of the concentration of stabilizer on the particle size is shown in Table 1. The result exhibited that the particle size reduced with the increasing of pluronic F68 concentration and finally a plateau region was reached at the concentration of $0.25 \% \mathrm{w} / \mathrm{v}$ (batch ESP4) from where the particle size no remarkably changed. However, at the concentration of $0.6 \%$ w/v (batch ESP8) and above, there were again remarkable changes obtained in particle size. The student ttest showed that there was significant difference $(p<0.05)$ in particle size of batch ESP4 compared with the batch ESP8. Similarly, in presence of Pluronic F127, plateau region was obtained at the concentration of $0.2 \% \mathrm{w} / \mathrm{v}$ (ESP13). But, at the concentration of $0.4 \% \mathrm{w} / \mathrm{v}$ (batch ESP 16) and above again significant changes $(p<0.05)$ in particle size was observed. After 15 days of nanosuspension preparation, batch ESP6 showed the least particle size changes. Thus, $0.4 \% \mathrm{w} / \mathrm{v}$ concentration of pluronic F68 was selected for formulating the other batches.

In this study, crystals were obtained at both lowest and highest drug concentration. At the lowest drug concentration $(2.0 \mathrm{mg} / \mathrm{ml})$, the crystal was grown to $468 \mathrm{~nm}$ after 15 days. However, at the highest drug concentration $(10.0 \mathrm{mg} / \mathrm{ml})$, comparatively larger crystal was obtained. These larger size crystals increased to 592 and $890 \mathrm{~nm}$, after 15 and 30 days, respectively (Table 2, Figure 1).

When drug concentration was between 3.0 $\mathrm{mg} / \mathrm{ml}$ and $5.0 \mathrm{mg} / \mathrm{ml}$, the initial particle size was $<200 \mathrm{~nm}$ but grew to approximately $400 \mathrm{~nm}$ after 30 days. In this range of drug concentration, the 
Table 1: Nanosuspension formulae for optimization of stabilizing agent $(n=3)$

\begin{tabular}{|c|c|c|c|c|c|c|}
\hline \multirow[t]{2}{*}{ Batch } & \multirow{2}{*}{$\begin{array}{c}\text { Pluronic } \\
\text { F-68 } \\
(\% \mathrm{w} / \mathrm{v})\end{array}$} & \multirow{2}{*}{$\begin{array}{c}\text { Pluronic F- } \\
127 \\
(\% \mathrm{w} / \mathrm{v})\end{array}$} & \multirow{2}{*}{$\begin{array}{c}\text { Mean } \\
\text { particle } \\
\text { size } \\
(\mu \mathrm{m})\end{array}$} & \multicolumn{3}{|c|}{$\begin{array}{c}\text { Mean particle size after ultrasonication } \\
(\mu \mathrm{m})\end{array}$} \\
\hline & & & & 0 day & 7 day & 15 day \\
\hline ESP1 & 0.1 & - & 14.33 & 2.16 & 3.28 & 5.12 \\
\hline ESP2 & 0.15 & - & 13.98 & 1.68 & 2.4 & 3.79 \\
\hline ESP3 & 0.2 & - & 14.10 & 0.847 & 1.64 & 2.78 \\
\hline ESP4 & 0.25 & - & 13.65 & 0.218 & 0.564 & 0.954 \\
\hline ESP5 & 0.3 & - & 13.14 & 0.147 & 0.212 & 0.343 \\
\hline ESP6 & 0.4 & - & 12.98 & 0.184 & 0.227 & 0.287 \\
\hline ESP7 & 0.5 & - & 12.87 & 0.226 & 0.282 & 0.378 \\
\hline ESP8 & 0.6 & - & 12.82 & 0.625 & 0.728 & 0.98 \\
\hline ESP9 & 0.8 & - & 12.94 & 0.89 & 0.98 & 1.12 \\
\hline ESP10 & 1.0 & - & 13.10 & 1.28 & 1.35 & 1.54 \\
\hline ESP11 & - & 0.1 & 12.94 & 1.30 & 1.58 & 1.97 \\
\hline ESP12 & - & 0.15 & 12.82 & 0.698 & 0.948 & 1.62 \\
\hline ESP13 & - & 0.2 & 12.65 & 0.265 & 0.382 & 0.518 \\
\hline ESP14 & - & 0.25 & 12.62 & 0.256 & 0.369 & 0.483 \\
\hline ESP15 & - & 0.3 & 12.67 & 0.264 & 0.387 & 0.514 \\
\hline ESP16 & - & 0.4 & 11.85 & 0.356 & 0.491 & 0.655 \\
\hline ESP17 & - & 0.5 & 11.54 & 0.564 & 0.854 & 1.28 \\
\hline ESP18 & - & 0.6 & 11.62 & 0.99 & 1.35 & 1.76 \\
\hline ESP19 & - & 0.8 & 11.91 & 1.04 & 1.34 & 1.85 \\
\hline ESP20 & - & 1.0 & 11.94 & 1.16 & 1.4 & 1.89 \\
\hline ESP21 & 0.1 & 0.1 & 15.14 & 0.891 & 0.945 & 1.21 \\
\hline ESP22 & 0.2 & 0.1 & 14.67 & 0.564 & 0.654 & 0.768 \\
\hline ESP23 & 0.15 & 0.15 & 14.45 & 0.517 & 0.597 & 0.682 \\
\hline ESP24 & 0.2 & 0.15 & 12.68 & 0.528 & 0.631 & 0.785 \\
\hline ESP25 & 0.2 & 0.2 & 13.14 & 0.84 & 0.9 & 1.12 \\
\hline
\end{tabular}

Each batch contained esomeprazole $(50 \mathrm{mg})$, methanol $(10 \mathrm{mg})$ and water $(20 \mathrm{mg})$

nanosuspension formulations also showed better stability than the other nanosuspensions with drug concentration $<3.0$ or $>5.0 \mathrm{mg} / \mathrm{ml}$.

\section{Effect of power input and duration of ultrasonication}

Crystal size decreased with increase in ultrasonic power input. However, particle size did not show any significant difference $(p>0.05)$ when power input was 60 and $65 \% \mathrm{~W}$.

The duration of ultrasonication also affected particle size. When the power input was $60 \% \mathrm{~W}$, the particle size of nanoformulations was reduced by increasing the ultrasonication time to $20 \mathrm{~min}$. However beyond the $20 \mathrm{~min}$, the time did not help the nanoformulations in reducing the particle size. When time length of ultrasonication was $5 \mathrm{~min}$ to $10 \mathrm{~min}$, some crystals deposited at the bottom of the container after three days. However, 20 min time length was sufficient to reduce particle size and prevent the crystal growth efficiently.

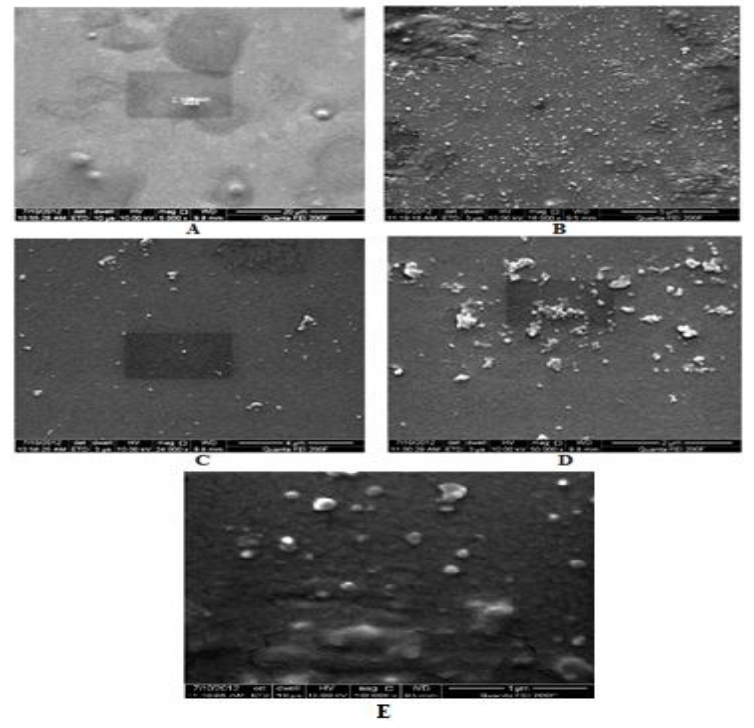

Fig 1: SEM images (x 104 magnification) of nanosuspension particles at acceleration voltage of 10 KV. Note: $A=$ particles after evaporative precipitation; $\mathrm{B}=$ particles after ultrasonication; $\mathrm{C}=$ particles agglomeration after 15 days; $D=$ particles agglomeration after 30 days; $\mathrm{E}=$ esomeprazole nanosuspension (batch ESP6d) 
Table 2: Optimization of drug concentration $(n=3)$

\begin{tabular}{cccccc}
\hline Batch & $\begin{array}{c}\text { Esome- } \\
\text { prazole }\end{array}$ & $\begin{array}{c}\text { Pluronic } \\
\text { F-68 }(\%\end{array}$ & \multicolumn{3}{c}{$\begin{array}{c}\text { Mean particle size } \\
\text { (nm) }\end{array}$} \\
\cline { 5 - 6 } & $\mathbf{m g})$ & w/v) & 0 day & $\begin{array}{c}\mathbf{1 5} \\
\text { day }\end{array}$ & $\begin{array}{c}30 \\
\text { day }\end{array}$ \\
\hline ESP6a & 20 & 0.4 & 365 & 468 & 620 \\
ESP6b & 25 & 0.4 & 242 & 460 & 580 \\
ESP6c & 30 & 0.4 & 132 & 165 & 215 \\
ESP6d & 35 & 0.4 & 159 & 174 & 192 \\
ESP6e & 40 & 0.4 & 125 & 182 & 204 \\
ESP6f & 45 & 0.4 & 156 & 212 & 328 \\
ESP6g & 50 & 0.4 & 184 & 287 & 418 \\
ESP6h & 55 & 0.4 & 258 & 345 & 475 \\
ESP6i & 60 & 0.4 & 245 & 352 & 492 \\
ESP6j & 70 & 0.4 & 274 & 372 & 483 \\
ESP6k & 80 & 0.4 & 387 & 495 & 692 \\
ESP6I & 100 & 0.4 & 432 & 592 & 890 \\
\hline
\end{tabular}

Particle size and polydispersity index (PDI)

The mean particle size of the selected batches (ESP6c to ESP6g) of nanosuspension is shown in Table 3. The nanoparticles size was found to depend on stabilizing agent and their amount. The smallest mean particle size of $147 \mathrm{~nm}$ was found in batch ESP5 and the largest mean particle size of $2.16 \mu \mathrm{m}$ in batch ESP1. The difference between particle size of these batches was significant $(p<0.05)$. After optimization of concentration of stabilizing agent, the batches (ESP6a to ESP6I) showed particle size in the range of $100-500 \mathrm{~nm}$; after optimization of drug and stabilizer concentrations, particle size was < $200 \mathrm{~nm}$. The particle size distribution curves for all these batches are unimodal and the difference between particle size of these batches was also not significant $(p>0.05)$. The polydispersity index (PDI) varied from 0.544 to 0.613 . Out of all the selected batches, ESP6d exhibited the lowest PDI.

Table 3: Optimized particle data (mean \pm SD, $n-3$ ) for selected esomeprazole batches

\begin{tabular}{cccc}
\hline Batch & $\begin{array}{c}\text { Mean } \\
\text { particle } \\
\text { size (nm) }\end{array}$ & $\begin{array}{c}\text { Zeta } \\
\text { potential } \\
(\mathbf{m V})\end{array}$ & $\begin{array}{c}\text { Polydispersity } \\
\text { index }\end{array}$ \\
\hline ESP6c & $132 \pm 20$ & $20.3 \pm 1.8$ & $0.54 \pm 0.05$ \\
ESP6d & $159 \pm 16$ & $25.5 \pm 1.3$ & $0.47 \pm 0.08$ \\
ESP6e & $125 \pm 12$ & $18.7 \pm 2.4$ & $0.57 \pm 0.11$ \\
ESP6f & $156 \pm 18$ & $15.9 \pm 2.1$ & $0.63 \pm 0.11$ \\
ESP6g & $184 \pm 20$ & $16.4 \pm 2.4$ & $0.61 \pm 0.13$ \\
\hline
\end{tabular}

\section{Zeta potential}

The zeta potential is the measure amount of charge on the particle and represents an index of particle stability. It is an important characteristic of nanoparticles which determines the physical stability of the formulation, in vivo distribution and targeting ability of nanoparticles.
Zeta potential was determined as a function of physical stability. The stabilizer was adsorbed onto the surfaces of the generated nanoparticles, which gave the zeta potential ranging from -15.9 to $-25.5 \mathrm{mV}$ (Table 3). Batch ESP6d showed the best zeta potential value ($25.5 \mathrm{mV})$.

\section{Morphological characteristics}

The particles of esomeprazole nanosuspension were spherical to oval in shape (Figure 1). Many particles in batches ESP6d and ESP6e showed smooth surface while those of batches ESP6f and ESP6c had a rough surface. The nanoparticle size as observed by SEM also correlated with size measured by Zetasizer.

\section{In-vitro drug release}

The in-vitro release of drug from stabilized nanosuspensions was studied by dialysis membrane diffusion technique. It is a very common method to estimate the \% release of drug from colloidal suspension.

Figure 2 shows the release profile of esomeprazole from different selected batches and pure drug in phosphate buffer of $\mathrm{pH}$ 7.4. The release profile of pure drug (control solution of esomeprazole) indicates very slow diffusion of esomeprazole with nearly $24 \%$ release in 60 min., while nanosuspensions showed a significantly enhanced release rate, $65 \%$ of the drug diffused in $30 \mathrm{~min}$ and $100 \%$ diffused in the 60 min test period. No significant $(P>0.05)$ difference in the in vitro release profile of selected batches (ESP6c, ESP6d, ESP6e, ESP6f and ESP6g) was observed.

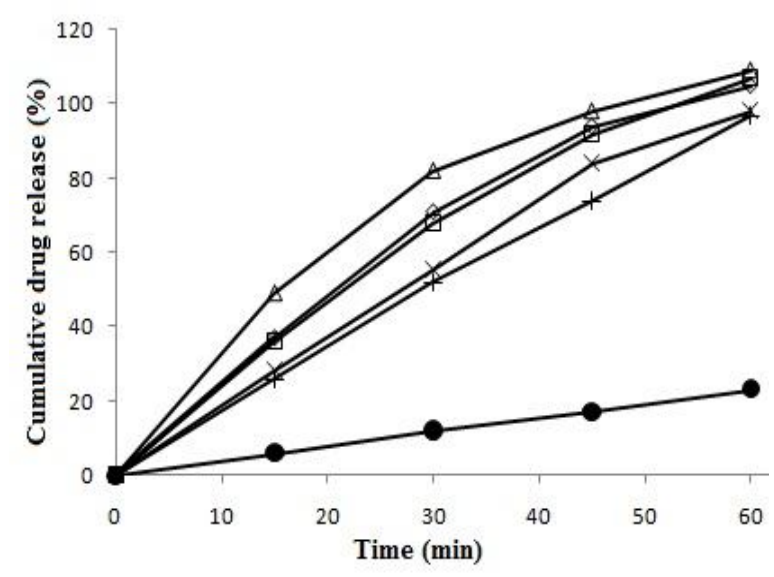

Fig 2: In-vitro drug release from selected esomeprazole nanosuspension batches esomeprazole solution (control) in phosphate buffer ( $\mathrm{pH} 7.4)$, Note: ESP6c $=\diamond ;$ ESP6d $=\square ;$ ESP6e $=\Delta ;$ ESP6f $=$; ESP6g $=+$; esomeprazole solution $=\bullet$ 


\section{Short-term stability of nanosuspension}

The physical appearance of ESP6d nanosuspension did not change when it was stored at $4^{\circ} \mathrm{C}$ for 2 months. A loose, thin layer of sediment was observed when nanosuspension was stored at $25^{\circ} \mathrm{C}$ for 2 months. However, the sediment disappeared with slight manual shaking. At room temperature storage for 2 months, particle size increased to $390 \mathrm{~nm}$. Mean particle diameter was $158 \mathrm{~nm}$ and $240 \mathrm{~nm}$ after storage at 4 and $25^{\circ} \mathrm{C}$, respectively, compared to $159 \mathrm{~nm}$ prior to performing the stability study. Thus the nanosuspension batch, ESP6d, was stable after 2 months of storage at $4^{\circ} \mathrm{C}$.

\section{DISCUSSION}

The evaporative precipitation ultrasonication method used for the production of esomeprazole nanosuspension can be described as a simple process comprising organic solvent, solvent, stabilizer, stirring and ultrasonication. In this method, the high energy generated as a result of the ultrasound led to erosion of the crystals and drug particles into nanoparticles. However, optimization of drug nanosuspension using this method is a complex process since it includes a lot of variables that affects the nanosuspension characteristics. Thus, this research work helped in identifying the different variables, such as the concentration of drug, concentration of stabilizer, duration of ultrasound and input power which may affect the drug release, stability of drug product and manufacturing process of nanosuspension. From this study, it was found that these significant variables also play a vital role in controlling the mean particle size and zeta potential in nanosuspension and after optimizing these variables it may be possible to prepare the nanosuspension having mean particle size of less than $200 \mathrm{~nm}$.

The large surface area of nanoparticles creates high total surface energy, which is thermodynamically unfavorable, resulting in a tendency to agglomerate to minimize the surface energy. Agglomeration can develop a variety of problems such as crystal growth, rapid settling, creaming [11]. So for overcome these problems Pluronic F-68 and/or Pluronic F-127 were used as a stabilizing agent in this study. The use of these stabilizers is often considered to have advantageous effect in formation of drug nanosuspension. The type and amount of stabilizers also produced a significant effect on the physical stability of nanosuspension. Thus stabilizers were used in different concentrations for managing the stability of different formulations (Table 1). The results revealed that batch ESP6 has better stability than the other batches and hence an appropriate concentration $(0.4 \% \mathrm{w} / \mathrm{v})$ of stabilizing agent (F68) was used for each drug concentration which enabled total crystal surface to become covered, thus providing the enough steric repulsion between the crystals. High concentration of stabilizing agent enhanced the viscosity of the suspension which produced the hindrance in transmission of ultrasonic vibrations and the diffusion between the solvent and antisolvent during precipitation, thus lead an increase in particle size.

Particle size formation can be explained by the theory of crystallization. This theory includes several steps like particle nucleation, molecular growth and agglomeration or aggregation. The driving force of this process is supersaturation which is useful in determining the nucleation rate and diffusion controlled growth rate. Higher the supersaturation leads the faster crystal growth [12].

The best result was obtained, when drug concentration was lies in between $3.0 \mathrm{mg} / \mathrm{ml}$ to $5.0 \mathrm{mg} / \mathrm{ml}$. However, at the higher drug concentration, due to greater supersaturation, a higher diffusion-controlled growth and agglomeration rate were achieved, resulting in larger initial crystal.

The mean particle size of nanosuspension decreased with the increase in ultrasinication power input. This phenomenon attributed to the increase erosion effect on the surface of large particles and particle agglomerates. However, the input power beyond the $60 \% \mathrm{~W}$ was not beneficial for reducing the particle size. In addition, the duration of ultrasonication also showed the similar effect on the particle size as of power input, and exhibited that longer time did not help for reducing the particle size. Hence, the optimal values of ultrasonic power input and duration were selected as $60 \% \mathrm{~W}$ and $20 \mathrm{~min}$, respectively.

After optimization of different variables, submicron sized particles with an average diameter in range of $100-500 \mathrm{~nm}$ were successfully produced. The results showed a dramatically decrease in particle size of esomeprazole nanoparticles compared with crude esomeprazole which has a mean particle size of $12.1 \mu \mathrm{m}$.

Following ultrasonication process, the diffusion rate of selected batches was dramatically improved. The diffusion rate of esomeprazole nanosuspensions was enhanced by more than 4fold compared with control (drug solution). 
Enhancement of release rate might due to the higher surface area of the nanosized drug particles available for dissolution as well as lowered diffusion layer thickness.

The sample stored at $4^{\circ} \mathrm{C}$, exhibited optimum stability due to the very low temperature. At this temperature, the solubility of esomeprazole decreased, leading to increased level of supersaturation and rapid nucleation. Since the number of nuclei increased, the solute on each nuclei decreased, and hence the potential for smaller crystals. Furthermore, low temperature decreases diffusion and growth kinetics at the particle boundary layer interface [13].

\section{CONCLUSION}

Esomeprazole nanosuspension has been successfully prepared by evaporative precipitation - ultrasonication method. The size of particles present in nanosuspension is highly dependent on process and formulation variables. Optimized formulations can be obtained in the nanoparticle size range of $100-200 \mathrm{~nm}$. The nanoformulations has good stability when Pluronic F68 concentration is $0.4 \% \mathrm{w} / \mathrm{v}$. Thus, evaporative precipitation- ultrasonication is a suitable method for the preparation of nanosuspension of poorly water-soluble drugs, such as esomeprazole, for enhancement of dissolution rate.

\section{ACKNOWLEDGEMENT}

The authors are very grateful to College of Pharmaceutical Sciences, Rajkumar Goel Institute of Technology, Ghaziabad, India, for providing a the required facilities for carrying out this study. The authors also wish to thank SMITA lab, Indian Institute of Technology (IIT), Delhi, India for assistance with SEM facilities.

\section{REFERENCES}

1. Lenhardt $L$, Vergnault $G$, Grenier $P$, Scherer $D$, Langguth $P$. Evaluation of nanosuspension for absorption enhancement of poorly soluble drugs: in vitro transport studies across intestinal epithelial monolayers. AAPS J, 2008; 10: 435-438.

2. Arunkumar N, Deecaraman M, Rani C. Nanosuspension technology and its applications in drug delivery. Asian J Pharm 2009; 3:168-173.

3. Keck CM, Muller RH. Drug nanocrystals of poorly soluble drugs produced by high pressure homogenization. Eur J Pharm Biopharm, 2006; 62: 3-16.

4. Nakarani $M$, Mishrs AK, Patel JK, Vaghani SS. Itraconazole nanosuspension for oral delivery: Formulation, characterization and in vitro comparison with marketed formulation. DARU J Pharm Sci, 2010; 18: 84-90.

5. Chingunpituk J. Nanosuspension technology for drug delivery. Walailak J Sci \& Tech, 2007; 4: 139-153.

6. Patel VR, Agrawal YK. Nanosuspension: An approach to enhance solubility of drugs. J Adv Pharm Technol Res, 2011; 2: 81-87.

7. Peters K, Leitzke S, Diederichs JE, Borner K, Hahn H, Muller RH, Ehlers $S$. Preparation of a clofazimine nanosuspension for intravenous use and evaluation of its therapeutic efficacy in murine mycobacterium avium infection. J Antimicro Chemo, 2000; 45: 77-83.

8. Kesisoglou F, Panmai S, Wu Y. Nanosizing-oral formulation development and biopharmaceutical evaluation. Adv Drug Dev Rev, 2007; 59: 631-644.

9. Singh SK, Srinivasan KK, Gowthamarajan K, Singare DS, Prakash D, Gaikwad NB. Investigation of preparation parameters of nanosuspension by top down media milling to improve the dissolution of poorly water soluble glyburide. Eur J Pharm Biopharm, 2011; 78: 441-446.

10. Moinard CD, Chevalier $Y$, Briançon S, Fessi $H$, Guinebretière S. Nanoparticles for drug delivery: review of the formulation and process difficulties illustrated by the emulsion diffusion process. J Nanosci Nanotechno, 2006; 6: 2664-2681.

11. Wu L, Zhang J, Watanabe W. Physical and chemical stability of drug nanoparticles. Adv Drug Dev Rev, 2011; 63: 456-469.

12. Xia D, Quan P, Piao H, Sun S, Yin Y, Cui F. Preparation of stable nitrendipine nanosuspensions using the precipitation-ultrasonication method for enhancement of dissolution and oral bioavailability. Eur J Pharma Sci, 2010; 40: 325-334.

13. Matteucci A, Hotze MA, Johnston KP, Williams RO. Drug nanoparticles by antisolvent precipitation: mixing energy versus surfactant stabilization. Langmuir, 2006; 22: 8951-8959. 